\title{
Medium Growth Rate
}

National Cancer Institute

\section{Source}

National Cancer Institute. Medium Growth Rate. NCI Thesaurus. Code C124824.

An indication that something is growing at an intermediate rate. 